\title{
UMA CHAVE PARA O CONHECIMENTO GEOGRÁFICO
}

\author{
Gabino Ribeiro Moraes*
}

RESUMO: Este artigo caracteriza-se por uma proposta de instrumentalização do ensino de Geografia na perspectiva da interdisciplinaridade. Uma experiência de simbiose entre Geografia e Literatura para alunos do terceiro ciclo do Ensino Fundamental. Os dados levantados sugerem a viabilização da obra A cha ve do tamanho, de Monteiro Lobato, como recurso didático na prática do ensino de Geografia. Além de facilitar o entendimento da noção de escala geográfica, esta proposta oferece, também, novas oportunidades para facilitar a compreensão da realidade local e global.

Palavras-chave: currículo; ensino de geografia; escala geográfica; literatura.

\section{INTRODUÇÃO}

Este artigo procura estabelecer e esclarecer percepções escalares. O raciocínio por escala em dimensão espacial ou temporal nasce da tentativa de instrumentalizar o ensino de Geografia, mais especificamente para discentes do $3^{\circ}$ ciclo do Ensino Fundamental, na vigência de um provável currículo oculto. A Literatura de Monteiro Lobato foi o instrumento pedagógico utilizado.

* Universidade Nacional do Timor Leste 
Nas mãos de uma criança a Literatura é um brinquedo, enquanto a Geografia tem importância singular na vida dos alunos, como seres espaciais. S eus lugares de convivência possibilitam o estabelecimento das primeiras relações com o local ou com o global. Monteiro Lobato, com sua literatura de espaço ${ }^{1}$, concretiza a necessidade de se criar histórias novas em espaço brasileiro. Movido pela paixão, foi político, nacionalista e sensível ao mundo infantil, transformou o capricho da imaginação em realidade, antecipou a descoberta da ciência na fantasia. Focalizado no processo de aprendizagem das crianças e aproveitando a curiosidade epistemológica infantil, ele potencializou a imaginação ao investigar como ocorre o processo de construção imagética de uma sociedade, como estão sendo interpretando os símbolos evocados para compor o imaginário social, os quais estão intrinsecamente relacionados com o lugar, ou seja, com o seu componente geográfico. Como aponta Corrêa (1999, p.178):

reafirmamos, como desdobramento das discussões acima, que todo imaginário social é também um imaginário geográfico, porque, embora fruto de um atributo humano - a imaginação - é alimentado pelos atributos espaciais não havendo como dissociá-los.

No vasto campo de pesquisa que o ensino de Geografia oferece, é importante que o professor/ pesquisador, ao eleger uma área específica para estudo, o faça a partir da sua experiência. No caso deste trabalho, tornou-se explícita a ligação entre G eografia e Literatura e busca-se concretizar a noção de que não existe docência sem discentes. Com essa experiência, começou-se a aceitar que o "formador" é o sujeito em relação a quem me considero o objeto, que o "educando" é o sujeito que me forma, e o "eu" é o objeto por ele formado. Ou seja, o educador, ou o formador, se forma e se re-forma ao

\footnotetext{
1 Tomada aqui como descrição dos espaços através da literatura.
} 
formar, quem é formado, forma a si mesmo ao ser formado. Propõe-se, com este trabalho, instrumentalizar o ensino de G eografia através da literatura.

\section{RACIOCÍNIO POR ESCALA}

Como recurso matemático fundamental da cartografia, a escala é e sempre foi uma fração que indica a relação entre as medidas do real e aquelas da sua representação gráfica. $\mathrm{O}$ conceito de escala pode assumir valores contínuos.

Nas últimas décadas, porém, exigências teóricas e conceituais impuseram-se a todos os campos da G eografia, e o problema da escala, embora ainda pouco discutido, começa a ir além de uma medida de proporção da representação gráfica do território, ganhando novos contornos para expressar a representação dos diferentes modos de percepção e de concepção do real. (CASTRO, 1995, p.129)

A discussão sobre o conceito de escala excede os limites da analogia geográfico-cartográfica, evidenciando outras possibilidades diante de novos níveis de abstração e de objetivação. Assim, a escala será problematizada como uma estratégia de aproximação do real, que inclui tanto a inseparabilidade entre tamanho e ambiente, o que a define como problema dimensional, como a complexidade dos fenômenos e a impossibilidade de apreendê- los diretamente, o que a coloca, também, como um problema fenomenológico.

A abordagem geográfica do real enfrenta o problema básico do tamanho, que varia do espaço local ao planetário. Esta variação de tamanhos e de problemas não é prerrogativa da geografia. Os gregos já afirmavam que, quando o tamanho muda, as coisas mudam: a arquitetura, a física, a biologia, a geomorfologia, a geologia, além de outras disciplinas, enfrentam esta mesma situação. Recentemente, as descobertas da microfisica e da microbiologia colocaram em evidência que na 
relação entre fenômeno e tamanho não se transferem leis de um tamanho a outro sem problemas e isto é válido para qualquer disciplina. (CASTRO, 1995, p.133)

O mundo de hoje está globalizado em todas as dimensões espaciais, sejam elas o bairro ou o país: o local e o global se encontram em uma íntima relação de proximidade. As abordagens teórico-metodológicas sintéticas e analíticas encontram-se desnorteadas com esta nova relação estabelecida entre o local e o global. Não é o ponto de partida - o bairro ou o mundo - que é significativo, mas, sim, o estabelecimento de relações entre eles.

D esta forma, para compreender o lugar de convivência, a criança precisa estabelecer muito mais relações do que sugerem os livros didáticos e o ensino tradicional.

O lugar assume na atualidade uma nova dimensão, sendo entendido como "o ponto de encontro de lógicas que trabalham em diferentes escalas, reveladoras de níveis diversos, e às vezes contrastantes, na busca da eficácia e do lucro, no uso de tecnologias do capital e do trabalho". O lugar é o ponto de encontro de interesses longínquos e próximos, locais e globais. (SANTOS, 1996, p.18-19)

Mudar de escala, em certo sentido, implica olhar algo de outro modo, mas, então, esse algo já não será o mesmo: aparecerá com nova fisionomia, dentro de outro contexto. A S egunda Guerra Mundial, na década de 40 do século XX, por exemplo, teve fortes e variados significados, não necessariamente os mesmos nas diversas dimensões: localmente, representou uma grande intervenção nas paisagens e maiores preocu pações em diversas proporções - do local ao global.

Estes raciocínios por escala quebram a lógica do pensamento binário simplista, aquele que somente lida com "sim" ou "não", com "é” ou "não é”, com classificações estáticas e permanentes (naturalizadas), tais como "fulano é rico e beltrano é pobre", "tal lugar é alto ou baixo". 
Raciocinar por escala é exercer o pensamento localizando- o claramente em um contexto. No livro A chave do tamanho, a personagem E mília reduz toda a humanidade. Tratase de uma "reinação" da boneca, que insiste em querer acabar com a II Guerra Mundial, e decide, para tanto, buscar as chaves que regulam o mundo. Para chegar até elas, a boneca faz uso do pó de pirlimpimpim, que a leva até a casa das chaves. Lá encontra várias chaves, e, sem saber qual delas é a da guerra, acaba por desligar a do tamanho. A humanidade fica pequena e o mundo se transforma. O livro de Monteiro Lobato, escrito durante a guerra, reflete, na tristeza de Dona B enta com o conflito, o sentimento do autor. Mesmo assim, as crianças se divertem com ele, que mostra a relatividade dos valores humanos e ensina política, organização social, ou ainda, escala geográfica com uma didática singular. Note-se que os critérios de classificação aparecem tão destacados quanto as referências ao contexto espacial, o que possibilita compre ender a classificação, investigar suas origens culturais e, ainda, discordar da classificação: em outros termos, colocar em discussão aquilo que seria naturalizado.

A questão da naturalização solicita o estudo dos processos sociais e naturais no espaço e no tempo, o que remete à questão do raciocínio por escala em suas dimensões espacial e temporal, buscando justamente negar ou evitar que acontecimentos e fenômenos sejam vistos como "dados do real", neutros, objetivos, eternos e imutáveis.

Quando se pensa em escala geográfica, considera-se a dimensão espacial dos processos, já a escala temporal diz respeito à abrangência temporal, ou duração dos processos rapidez e lentidão, ritmo e intensidade são noções associadas. Não se pode deixar de, também, colocar em primeiro plano a experiência subjetiva do tempo.

Tem-se a tendência de tratar separadamente a escala espacial e a escala temporal, porém, em qualquer estudo é pre ciso integrá-las, investigando suas relações. Comumente, os 
livros didáticos trazem uma sequência de atividades sobre a casa do aluno, a rua onde mora, seu bairro, sua cidade, município, etc., seguindo exatamente esta ordem. A casa é muito próxima do aluno, significativa, no entanto, o trajeto casa-escola, o bairro e, até mesmo, a cidade, de modo mais ou menos limitado, também fazem parte de suas experiências corporais, então, pode-se perguntar se esta sequência, entendida como sendo do menor para o maior (ou do mais próximo e significativo para o mais distante) constitui a única via de estudo.

Na mesma sequência de atividades, rua, bairro e cidade são, habitualmente, pensados separadamente. Com o eixo do raciocínio por escala pretende-se, com inspiração em Yves Lacoste (1988), apresentar uma outra possibilidade: refletir sobre o espaço, com seus processos sociais e naturais, por meio da articulação de escalas.

Um modo simples de introduzir a questão é chamar a atenção dos alunos para a dimensão espacial daquilo que já vivenciam ou estudam. Em uma planta da cidade, eles podem delimitar o bairro onde moram e também a área que mais conhecem, aquela realmente percorrida, experimentada cotidianamente. Talvez exista um estabelecimento comercial ou uma festa popular (típicos de certos locais da cidade) restritos a este bairro, que, talvez, abrigue comunidades de migrantes (e aqui entra a relação com outros espaços, exigindo trabalho em mais de uma escala). Em um dia de inverno, talvez seja possível observar a neblina localizada apenas sobre um rio, ou no fundo de um pequeno vale, e em outro dia, um nevoeiro tomando toda a cidade.

Na sequência de atividades comentada há pouco, se a rua é pensada não apenas de modo isolado, mas no contexto do bairro, dentro da cidade, articulada a estes espaços maiores, fica facilitada, por exemplo, a compreensão do movimento de pessoas e de veículos, uma vez que este movimento não é apenas dos que moram no bairro, mas também dos que vêm até ele comprar, passear ou visitar, ou dos que 
passam por ele a caminho de outros bairros. Aqui também se pode trabalhar as alterações de sentido: para os moradores, o bairro é local de moradia, para os moradores da cidade, é passagem (é sempre importante lembrar que, se os sentidos mudam, mudam também as ações realizadas no lugar, as possibilidades de permanência e transformações). Por outro lado, se se quer aprender sobre as pessoas, as famílias dos moradores, as relações cotidianas entre os moradores, certamente sente-se necessidade da história e ampliase a escala do estudo (no sentido espacial e no temporal): de onde vieram? quando nasceram?

A imagem que as crianças constróem de um córrego, e dos problemas a ele relacionados, permanece a mesma depois que visitam e estudam não apenas o pequeno trecho próximo à escola, mas toda, ou grande parte de sua extensão? Viver as duas experiências, compará-las e integrá-las constitui rica reflexão sobre escala geográfica. $\mathrm{O}$ que viram na primeira experiência? Quais problemas foram apontados? E na segunda experiência? O que foi diferente? Mudaram as explicações?

O interessante não é apenas realizar um estudo desta ou daquela maneira, seguir este ou aquele caminho, utilizar um ou outro procedimento trabalhando nesta ou naquela escala e articulando escalas, mas, sim, construir os caminhos com os alunos, promovendo discussões sobre os próprios caminhos, sobre os porquês de suas escolhas, sobre seus limites, sobre os conhecimentos produzidos daquela maneira (se são suficientes, se deixam dúvidas, quais dúvidas, o que se pode afirmar com certeza e o que se afirma sem tanta certeza, entre outros questionamentos).

Também é preciso esclarecer que não se defende a idéia de uma simples imposição dos processos de grande escala sobre os de pequena escala. O que está sendo proposto é o estudo de como se relacionam as diversas escalas, ou melhor, os fenômenos e processos de diversas escalas, em cada situação. 
Quanto à escala temporal, já se afirmou que ela se refere à duração dos processos. Neste sentido, raciocinar por escala temporal é colocar a questão do tempo, mais especificamente de sua duração, na definição e na investigação de qualquer problemática. E este pode ser o tempo da natureza, o tempo histórico e também o tempo subjetivo.

Todos os jogos e brincadeiras têm a mesma duração? Por quê? (O questionamento do motivo foi colocado para estimular a elaboração de interpretações e não a enunciação de verdades.) E as atividades na escola? Quanto tempo cada uma delas ocupa? Como se pode interpretar tal organização do tempo? C omo é o dia de cada aluno? Quais são suas atividades diárias? Qual a duração dessas atividades? Que diferenças existem em relação à rotina de seus pais? Por quê? A partir de entrevistas, filmes, textos de jornais e livros, é interessante comparar o cotidiano dos alunos com o de crianças de outras classes sociais, de outros contextos culturais ou de outros períodos históricos.

O tempo subjetivo frequentemente emerge por meio da expressão dos próprios alunos: em um dado dia, uma atividade rotineira é sentida como "mais demorada" para alguns, um determinado intervalo de tempo é muito longo, para outros, muito curto, alguém pode questionar um limite assinalado pelo tempo, etc. Estas são ocasiões riquíssimas para que se discuta sobre o que os alunos sentem e pensam a respeito do tempo. As discussões podem ser continuadas, de modo a levá-los a pensar sobre como estas idéias de duração (e também de extensão) são construídas nos mais diversos contextos culturais: o que é longe, o que é perto, o que é rápido, o que é demorado, em diversas situações, para pessoas que moram em Porto Alegre, para pessoas que moram em Viamão, para ricos e para pobres, para jovens e para velhos.

Quem vive em cidades grandes, como Porto Alegre, dizer que um lugar a vinte minutos de distância, de carro, é perto. Para quem vive em Viamão, um lugar a estes mesmos vinte minutos de distância, de carro, é sentido como distante. 
A inconveniência da analogia entre as escalas cartográficas e geográficas existe em virtude do fato de que a $\mathrm{G}$ eografia não dispõe de um conceito próprio de escala e adotou o conceito cartográfico. Não é evidente, contudo, que esta noção lhe seja apropriada, pois a escala cartográfica exprime a representação do espaço como forma geométrica, enquanto a escala geográfica exprime a representação das relações que as sociedades mantêm com esta forma geométrica.

Cada um a seu jeito, os geógrafos behavioristas e os marxistas baseiam seus estudos dos processos na escolha de escalas geográficas diferentes, sem que infelizmente seja explicitada, pelo menos na maioria dos casos, essa distinção fundamental entre escala cartográfica e geográfica. (RACINE et. al., 1983, p.125)

Este é um problema fundamental na busca de compreensão da articulação de fenômenos em diferentes escalas, bem como na constatação de que os fatos sociais são necessariamente relacionais.

\section{ESCALA GEOGRÁFICA E LITERATURA}

Um ponto de partida relevante para se refletir a construção de conhecimentos geográficos, na escola, parece ser o papel e a importância da G eografia para a vida dos alunos. Há um certo consenso entre os estudiosos de metodologia de ensino de que o papel da Geografia é o de prover bases e meios de desenvolvimento para a ampliação da capacidade de apreensão da realidade dos alunos sob o ponto de vista da espacialidade, ou seja, da compreensão do papel do espaço nas práticas sociais e destas práticas na configuração do espaço.

Ao longo da História, os seres humanos organizaram-se em sociedade e produziram sua subsistência, constituindo, assim, seu espaço, que se configura conforme os modos cultu- 
rais e materiais de organização dessa sociedade. Há, neste sentido, um caráter de espacialidade em toda prática social, assim como há um caráter social na espacialidade.

Além disso, o pensar geográfico contribui para a contextualização do próprio aluno como cidadão do mundo ao contextualizar espacialmente os fenômenos, levando-o a conhecer o mundo em que vive, desde a escala local às escalas regional, nacional e mundial. O conhecimento geográfico é, pois, indispensável à formação de indivíduos participantes da vida social na medida em que propicia o entendimento do espaço geográfico e do papel deste espaço nas práticas sociais.

A espacialidade em que os alunos vivem na sociedade atual, como cidadãos, é bastante complexa. S eu espaço, diante dos processos de mundialização e multiculturalismo da sociedade, extrapola o lugar de convívio imediato, sendo traçado por uma figura espacial fluida, sem limites definidos. $\mathrm{E} m$ razão desta complexidade crescente, o cidadão não consegue, espontaneamente, compreender seu espaço de modo mais articulado e crítico. Sua prática diária permite-lhe apenas um conhecimento parcial e frequentemente impreciso do espaço. $\mathrm{O}$ conhecimento mais integrado da espacialidade requer uma instrumentalização.

A construção e a reconstrução do conhecimento geográfico pelo aluno ocorrem não apenas na escola, mas também fora dela. Entretanto, a ampliação de tais conhecimentos, a ultrapassagem dos limites do senso comum, o confronto de diferentes tipos de conhecimento e o desenvolvimento de capacidades operacionais do pensamento abstrato são processos que podem ser potencializados com práticas intencionais de intervenção pedagógica. A obra $A$ chave do tamanho pode ser utilizada como um instrumento facilitador de obra literária, de livro didático, de chamariz, de âncora afetiva e de canal de entrada para o lúdico. A utilização do texto de Monteiro Lobato justifica-se pela multiplicidade de etnias 
dos personagens do Sítio do Pica-pau Amarelo, pela democratização das relações intersubjetivas, sem que se escamoteiem os conflitos, aspectos que norteiam o projeto de literatura infantil de Lobato. E stas e outras são características da sociedade anunciada como uma espécie de contraponto à complexa montagem, discursiva e tecnológica, de controle das consciências presente nas formas organizacionais típicas da atualidade.

\section{LOBATO E A EDUCAÇ̃̃O}

A aproximação entre a Literatura e a G eografia permite estabelecer relações intertextuais e reconhecer as divergências entre os discursos. Em outras palavras, ao se trabalhar com conceitos da geografia literária ${ }^{2}$, revela-se o que há de literário na própria produção da G eografia. Esta prática possibilita reconhecer as estratégias argumentativas, as marcas da escritura e os tipos de metáfora empregados, permitindo uma leitura e uma redação mais precisas sem dispensar, é claro, a consciência epistemológica e metodológica.

O objeto geográfico é contemplado pela obra literária. O devaneio poético ${ }^{3}$ descortina significados mais abrangentes do que aqueles forçosamente coerentes e racionais da Ciência, insuflando a imaginação geográfica. Nas palavras de Monteiro, a noção de lugar, embora sendo obra de imaginação e de criação literária, contém uma verdade que pode estar além daquela advinda da observação acurada, do registro sistemático de fatos:

2 Essa geografia literária, entretanto pode se referir a duas coisas muito diferentes. Pode indicar o estudo do espaço na literatura ou, ainda, da literatura no espaço.

3 Todos os sentidos despertam e se harmonizam no devaneio poético É essa polifonia dos sentidos que o devaneio poético escuta e que a consciência poética deve registrar (B ACHELARD, 1988, p. 2). 
E sta capacidade paradoxal encontrável na Literatura, ou a ela conferida pelo geógrafo, brota de um reconhecimento de que a essência ou a verdade do mundo transcende à interpretação de dados coligidos por geógrafos, historiadores e sociólogos. (MONTE IRO, 2002, p.65)

A imagem de Monteiro Lobato está encoberta por um tipo de fama que mais atrapalha do que ajuda, seja na iluminação dos méritos do autor, seja na leitura atual de sua obra, cujo quadro de referência já se vai tornando longínquo demais para nós. Lobato foi, acima de tudo, um agitador de idéias, um polemista agressivo e irreverente que dedicou a vida à missão de denunciar as mazelas do atraso nacional. Pouco dessa efervescência de espírito restou sob a aura convencional, verde-e-amarela, que lhe imputaram à medida que ele passou a ocupar, nos anos 50 do século XX, posição central no sistema escolar brasileiro.

A partir dos anos 70, Lobato foi deslocado por uma geração de educadores que submeteu sua obra a uma revisão de cunho progressista. Influenciados pelo revival de Oswald de Andrade e da vertente modernista mais radical, então em curso, estes professores passaram a incriminar Lobato por seu conservadorismo acerca da pintura, fixado desde a crítica feroz que ele publicou em 1917 contra a pintora Anita Malfatti. Realçaram-se, ao mesmo tempo, os supostos traços de racismo encontrados nos livros do escritor ${ }^{4}$ e que, se o desabonavam junto ao público adulto, tornavam- no proibitivo, segundo aqueles educadores, para as crianças. $\mathrm{O}$ amoralismo de E mília, sua maior personagem, voltou a incomodar, só que dessa vez não pela insolência crítica da boneca, mas pelo alegado reacionarismo de Lobato ${ }^{5}$.

4 Racismo suposto devido ao fato de Tia Anastácia, personagem afro- descendente, ser representada como uma pessoa simplória, tola e supersticiosa.

5 Devido à sua postura diante dos jovens criadores da S emana de 1922. 
E m vez de desfazer a anterior, a nova imagem se combinou àquela para inverter seu sinal: Lobato passou a ser tudo o que ele mais abominara em vida e jamais supôs que a posteridade poderia associar a seu nome, a saber, um autor oficialesco, de panteão, conformista tanto do ponto de vista social quanto ideológico e literário. Como sintoma, talvez, deste ambiente refratário, uma série de brincadeiras malévolas surgiu em torno de sua literatura para crianças (associando o pó mágico da ficção com a cocaína), e o autor - com seu pó de pirlimpimpim, seus narizinhos e rabicós - chegou a ser tomado como um autor não apenas secundário e ultrapassado, mas francamente ridículo.

Furacão na Botocúndia, perfil biográfico e intelectual do Lobato, parece imbuído desta abordagem e bem-sucedido ao executá-la. O livro estabelece uma série de correções a respeito da posição do autor no contexto do Modernismo dos anos 20 e extrai, da figura da estátua de bronze, uma fisionomia outra vez de carne e osso. A biografia clássica de Lobato, monumental à sua maneira, é de 1955, escrita pelo amigo e apologista E dgard C avalheiro ${ }^{6}$. Furacão na Botocúndia é, possivelmente, o primeiro trabalho com o mesmo escopo que se publica desde então.

$\mathrm{Um}$ dos aspectos que mais se destaca, nas narrativas biográficas, é a paixão de Lobato pelo empreendimento produtivo, pelo trabalho voltado à multiplicação da técnica e da riqueza, pelo capitalismo, em suma, na sua feição mais intrépida, que só encontra paralelo na completa inaptidão do autor para qualquer atividade prática. É como se ele fosse escritor em excesso para que pudesse ser homem de negócios, e vice-versa. Na vida prática e material, Lobato fracassou sucessivamente como fazendeiro, como editor de livros e como explorador de petróleo. Têm razão os biógrafos que alegam

6 CAVALHE IRO, E. Monteiro Lobato: vida e obra. Vol. 1 e 2. São Paula C ompanhia Editora Nacional, 1955. 
ter ele deixado, com suas campanhas fulgurantes, sementes que, de uma forma ou de outra, frutificaram mais tarde. Quase nunca como ele gostaria. Podem ter razão, ainda, quando invocam motivos externos, de força maior, para os fracassos empresariais de Lobato.

Para Lobato, o B rasil autêntico não era o do litoral, muito influenciado pelas modas parisienses, mas o do interior. S eu único mal era a pobreza, imposta pelo poder do latifúndio. Acusaram Lobato de separatista, de vendido aos Estados Unidos, e, por fim, de comunista, mas ele passou a vida a lutar pelo progresso, pela riqueza do B rasil, sem cuidar de si, sem tirar nenhum proveito pessoal das campanhas a que se atirou. S egundo Anísio Teixeira, grande educador que foi uma das numerosas descobertas beneméritas de Lobato, o grande drama do criador de Narizinho foi nunca ter podido dar "toda a medida do seu gênio". (NUNES, 2000, p. 25)

E mbora fosse um editor brilhante, no âmbito da literatura adulta, seus empreendimentos se esboroaram como se fossem reflexos de suas aventuras no mundo dos negócios. A literatura talvez requeira um afastamento, em face da dimensão prático-normativa da vida e uma capacidade de criar todo um tecido de intermediação, cerne de sua autonomia, que Lobato, tomado pelo sentido da urgência mais imediata, não podia alcançar. Sua ficção para adultos é aplicada, mas protocolar. Seus contos raras vezes transcendem o causo interiorano, a ansiedade por suscitar efeitos de terror ou humorismo aflorando a todo momento. Pode-se falar, como acerca de tudo o que Lobato escreveu, que sua literatura não-infantil era uma literatura de intenções.

O impasse contido neste diagrama, que enclausura Lobato em uma zona morta a meio caminho entre vida literária e vida prática, forçando- o a uma atividade tão incessante quanto aparentemente estéril, encontrou seu ponto de fuga na literatura para crianças. Já se observou que esta literatura serviu simultaneamente a Lobato como desaguadouro de 
ressentimento e como suave vingança, implantada na mentalidade das gerações futuras, sobre seus adversários e detratores. $\mathrm{O}$ que não foi suficientemente ressaltado é que a literatura para crianças, ao contrário do que parece, está mais próxima da vida prática do que a literatura para adultos, devido ao seu conteúdo inevitavelmente formativo e às suas finalidades não-literárias. Além disso, esta literatura também se encontra suspensa em um ponto intermediário entre ação e representação, entre atitude moral e obra de arte.

De escrever para marmanjos, já enjoei. Bichos sem graça. Mas, para as crianças, um livro é todo um mundo. Ainda acabo fazendo livros onde nossas crianças possam morar, como morei no "Robinson" e nos "Filhos do Capitão G rant". (LOBATO, 1972, p. 334)

Esta declaração de J osé B ento Monteiro Lobato, feita em 1926, cinco anos depois do lançamento de sua primeira obra infantil, Reinações de Narizinho, era bastante profética. Até praticamente a década de 80 , as crianças continuaram lendo e "morando" nas suas obras. U ma pesquisa realizada em 1974 demonstrou que 140 em 200 crianças preferiam as obras de Monteiro Lobato às histórias [historinhas] em quadrinhos de Walt Disney. Levada para a televisão em meados da década de 70, a série O Sítio do Pica-pau Ama relo veio confirmar esta preferência. Atualmente, existe uma nova adaptação televisiva da obra, acompanhada por um imenso leque de produtos de consumo (desde brinquedos e itens de vestuário infantil até histórias em quadrinhos).

C om Lobato, surgiu uma literatura brasileira para crianças que até então se conformavam (e se formavam) apenas com histórias de príncipes e princesas encantadas com nomes estrangeiros de difícil pronúncia. Anticonvencional por natureza e com idéias avançadas para sua época, Monteiro Lobato criou um mundo de faz-de-conta, onde realidade e sonho não tinham fronteiras definidas, e o pó de pirlimpimpim 
era tão aceito e digno de crédito quanto os célebres bolinhos da Tia Nastácia, devorados pelos habitantes do Sítio do Picapau Amarelo.

Monteiro Lobato reconhecia não haver uma fórmula definida de sucesso para um livro infantil. Na tentativa de não menosprezar a inteligência infanto-juvenil, e reformulando a pedagogia da sua época, o escritor afastou-se do misticismo, da superstição e da fantasia mórbida, presentes no imaginário das crianças brasileiras durante séculos. Para surpresa geral, demonstrou para seus pequenos leitores que a inteligência bem orientada acaba sempre vencendo a força bruta, e que um plano bem executado vale mil vezes mais do que o mais potente dos muques.

A situação era tão nova que as suas velhas idéias não serviam mais. E mília compreendeu um ponto que Dona B enta havia explicado, isto é, que nossas idéias são filhas da nossa experiência. Ora, a mudança do tamanho da humanidade vinha tornar as idéias tão inúteis como um tostão furado. A idéia duma caixa de fósforos, por exemplo, era a idéia duma coisinha que os homens carregavam no bolso. Mas com as criaturas diminuídas a ponto de uma caixa de fósforos ficar do tamanho dum pedestal de estátua, a "idéia de caixa-defósforos" já não vale coisa nenhuma. A "idéia- de-leão" era a dum terrivel e perigosíssimo animal, comedor de gente; e a "idéia- de-pinto" era a dum bichinho inofensivo. Agora é o contrário. $\mathrm{O}$ perigoso é o pinto.

E mília sentiu um friozinho no coração. Começou a desconfiar que havia feito uma coisa tremenda, a coisa mais tremenda jamais acontecia no mundo.

Pensou, pensou, pensou. Depois resolveu calcular que tamanho teria. (LOBATO, 1972, p.18)

Acima de tudo, seus livros tinham como objetivo ensinar a criança a ter raciocínio próprio e visão crítica do mundo. 
Por meio dos personagens de O Sítio do Pica-pau Ama relo, Monteiro Lobato revelava sua visão de mundo. Inconveniente e franca, Emília, uma boneca de trapos, diz sempre a verdade, pois nunca viveu em sociedade e ainda não sabe mentir. O Visconde de S abugosa, apesar de sábio e pedante, verdadeiro "rato de biblioteca" e desligado da vida, sabe das coisas e as antecipa, como, por exemplo, a existência de petróleo no B rasil, em uma época em que ninguém acreditava nesta possibilidade (com exceção de Monteiro Lobato), "descobrindo" um poço no Sítio. Pedrinho e Narizinho representam a infância normal e livre, e D ona B enta, a avó sonhada por todos, expõe os fatos direta e claramente.

No decorrer de 22 livros, o escritor contou, com seu modo descontraído e saboroso, fatos mitológicos, políticos, sociais, históricos, científicos. Ensinou Matemática, Português, G eografia e Astronomia, e, mesmo escrevendo para crianças, manteve o estilo claro e objetivo de sua obra para adultos, acrescentando- lhe uma abertura para subverter as regras da gramática e do dicionário ao inserir elementos da oralidade em sua prosa. Um dos traços mais visíveis a garantir o êxito da obra é o caráter imediato da narração tudo é descrito vivamente e de modo rápido.

A obra infantil de Lobato caracteriza-se pela vontade de libertação. O moralismo convencional foi abolido, como o foram as sugestões religiosas. Lobato, antes de tudo, louvou a vida, e não será difícil descobrir em seus textos em prosa uma filosofia de vida. Através de seus livros, percebe-se que ele acreditava na inteligência das crianças, mas seu desligamento das convenções da época gerou uma fanática e mesquinha campanha contra seus livros: um sacerdote chegou a escrever um volume tentando provar que Lobato pregava o comunismo para as crianças.

Livres, tanto em estilo quanto em inspiração, as obras para crianças de Monteiro Lobato foram, em uma determinada época, perseguidas por alguns educadores e pedagogos 
limitados. Na verdade, a E mília inconveniente e franca - considerada, em certos aspectos, um alter ego de seu criador não podia agradar a espíritos conservadores. Tampouco D ona B enta, com a sua lucidez não-repressora, ou qualquer outro dos personagens: Tia Nastácia, a cozinheira; o Marquês de Rabicó, um porco falante; o rinoceronte Quindim; Pedrinho e Narizinho; ou o cientificista Visconde de Sabugosa. Também os setores ultraconservadores da Igreja Católica atacaram Lobato, acusando-o de ateísmo por dar vida a bonecas de pano e a sabugos de milho.

Na dinâmica dos personagens de Monteiro Lobato cabe à fantasia da criança-leitora (e, mais tarde, telespectadora) um espaço ativo de criação, ou de complementação criativa frente aos personagens. Ele comprovou que uma boneca de pano ou um sabugo de milho (E mília e o Visconde de S abugosa) podem estimular a criatividade das crianças exatamente por sua forma incompleta, inacabada. A boneca de pano - velha, amassada e mal-feita - permite à criança realizar personificações inusitadas, muito mais ricas e criativas do que aquelas permitidas pelos brinquedos bem-acabados industrializados e comercializados atualmente, que "dizem mamãe", "sabem mamar" e até "fazem xixi".

Uma espiga de milho, com toda a sua carga simbólica, estimula a fantasia infantil, pois pode tornar-se aquilo que a criança desejar em suas brincadeiras, ao passo que o produto industrial completo e acabado, embora tenha uma aparência deslumbrante, deixa pouco ou nenhum espaço para a complementação criativa da criança. B rinquedos ou bonecos, por mais bonitos e sofisticados que sejam, quando apresentam signos acabados e fechados empobrecem a relação da criança com o próprio imaginário. F elizmente o computador, de certa maneira, pode despertar e libertar o imaginário da criança, assim como o livro ou o rádio (este último pouco utilizado pelas crianças no B rasil).

Um time de botões acaba por ser mais usado que um trem elétrico, exatamente porque cada uso implica novas 
mensagens esurpresas. O brinquedosofisticadoé deslumbrante para a criança na hora que o recebe, em seguida, porém, re duz-se o nível de interesse, porque a mensagem se esgota no breve uso: não o transcende, como ocorre em "invenções" semiacabadas, toscas, ajustadas ou feitas pelas crianças. (É claro que o brinquedo industrial tem e pode ter outras qualidades. Com o advento da eletrônica, brinquedos industrializados re cuperaram parte de seu efeito criativo e de sua função de ativadores tanto do imaginário quanto do raciocínio.)

Lobato alcançou intuitivamente o efeito do acima descrito, pois viveu em um B rasil pré-industrial, época em que o brinquedo sofisticado era apenas o brinquedo importado, exclusivamente ao alcance de crianças com maior poder aquisitivo. Daí haver criado, na boneca de pano e no sabugo do milho, alguns personagens em permanente "fazer-se", incompletos, estimulando uma espécie de fetichismo às avessas.

A televisão pretendeu mostrar o Lobato educador mais do que o Lobato professor, instrutor, por isso foram preferidas as obras mistas e de diversão Fazer predominar o equilíbrio entre a diversão e a instrução mostra que a decisão pedagógica do grupo encarregado de tele-encenar Lobato foi a de operar sobre a idéia de educação da sensibilidade e da cidadania como prioritária e melhor condutora dos valores de vida.

Se houvessem optado pelo didatismo ou pela mera instrução, seguramente ter-se-ia chegado ao segundo ano de programa com um desinteresse cruel ou um didatismo condenável, em se tratando de televisão. O programa alcançou nove anos com crescente interesse, apesar de ser exibido em horários de baixa audiência. E, anos depois, em plena década de 90, a TVE continuou a apresentar reprises de episódios do Sítio.

Visionário, Lobato imagina, por exemplo, uma espécie de Internet em uma de suas obras infantis. O autor prevê a violência do trânsito, clama por uma nova escrita da história, antecipa relações comerciais e literárias no mercado literário brasileiro (implanta a consignação neste mercado), forja a 
industrialização e critica o Rio de J aneiro como sede da capital federal. E m A reforma da natureza, de 1941, escreve sobre plantas e animais transgênicos, e quando narra $O$ poço do Visconde, de 1937, prevê até o local do primeiro poço de petróleo brasileiro, encontrado em 1939 em uma localidade baiana, ironicamente denominada Lobato.

E m uma carta enviada a seu amigo Godofredo Rangel, em 1904, resume as forças em jogo em sua vida: "Eu sou um homem-toupeira que cava subterraneamente as veneráveis raízes das mais sólidas verdades absolutas”. O contista J osé B ento metamorfoseia-se na contadora de história D ona B enta, uma entre seus alter egos, a desfiar para as crianças um mundo de histórias mágicas, recheadas de conhecimento.

Para mudar o B rasil, Lobato transforma-se em pedagogo, e não é por acaso que um de seus melhores amigos, o homem que mais admirava depois de Machado de Assis, era o educador Anísio Teixeira. Esta simbiose entre ensino e literatura cria uma enciclopédia do saber.

Mas, afinal, a literatura infantil de Monteiro Lobato é composta por obras literárias ou por livros didáticos? Para analisar as relações entre obra literária e livro didático é indispensável refletir sobre uma percepção do sistema escolar:

Esta dificuldade - nosso embaraço em encontrar as formas de luta adequadas - não virá de que ainda ignoramos o que é poder? Afinal de contas foi preciso esperar o século XIX para saber o que era a exploração, mas talvez ainda não se saiba o que é poder... S abe-se muito bem que não são os governantes que o detêm. Mas a noção de "classe dirigente" não é nem muito clara nem muito elaborada. Dominar, dirigir, governar, grupos no poder, aparelho de E stado, etc. é todo um conjunto de noções que exige análise. Além disso, seria necessário saber até onde se exerce o poder, através de que revezamentos, e até que instâncias, frequentemente ínfimas, de controle, de vigilância, de proibição, de coerção. Onde há poder, ele se exerce. Ninguém é, propriamente falando, seu titular, e, no entanto ele sempre se exerce em determinada direção, com uns de um lado e 
outros do outro, não se sabe ao certo quem o detém, mas se sabe quem não o possui. (FOUCAULT, 1988, p.46)

O fragmento acima aponta para uma questão atualmente essencial: como entender a escola - e, no seu interior, o livro didático - no papel de relação social de dominação e de poder. E videnciando o problema fundamental da escola e do material didático, estas relações sociais se revelam através do conteúdo de tais livros: burguês ou proletário, ideológico ou científico.

$\mathrm{G}$ raças a autores como Michel Foucault, entre outros, sabe-se que tal percepção é enganosa e simplificadora. A escola como locus de poder não se resume ao conteúdo que transmite aos alunos. Aliás, o conteúdo é provavelmente menos importante do que outros procedimentos característicos do sistema escolar, tais como a hierarquia e a autoridade, a crença nos fatos objetivos, a avaliação e a promoção, os diversos gêneros de escola e suas relações com a reprodução das desigualdades sociais, a divisão acadêmica do conhecimento. No fundo, não existem conteúdos que sejam em si revolucionários: qualquer conhecimento, qualquer teoria ou conceito pode servir como instrumento para a dominação cultural.

Também há, por exemplo, a inculcação sub-reptícia de uma visão burguesa do tempo, na exigência de pontualidade, na importância das horas e minutos, na passagem do tempo vivido para tempo gasto, como valor de troca e não mais apenas valor de uso. (THOMPSON, 1979, p.239-293)

D o mesmo modo, transmite-se a percepção dos objetos e das pessoas (carteiras, alunos, quadro-verde, lugar do professor, etc.) em uma sala de aula característica do final do século XVIII. E, independentemente do conteúdo transmitido (que pode ser modos de produção, escala, burguesia versus proletariado ou globalização, entre outros), a própria forma de apresentar estes conteúdos já revela e reforça uma faceta da dominação: a verdade pronta, reproduzida pelo professor e assimilada pelo aluno como produção do saber alheia à prática educativa. 
O livro didático constitui um elo importante na corrente do discurso da competência: é o lugar do saber definido, pronto, acabado, correto e, dessa forma, fonte última de referência e contrapartida dos "erros" das experiências de vida. Este "manual", apesar de não ser (como pretendem alguns teóricos da educação) o grande culpado pelo autoritarismo e pela precariedade no ensino, acaba consubstanciando a sua forma usual e institucionalizada como o saber competente alheio à prática educativa, e passa a ser assimilado pelos alunos.

Contudo, é possível manter uma outra relação com o livro didático. O professor pode e deve encarar o "manual" não como o definidor de todo o seu curso, de todas as suas aulas, mas fundamentalmente como um instrumento que está à serviço dos seus objetivos e de suas propostas de trabalho. Trata-se de usar criticamente o "manual", relatitivizando-o, confrontando-o com outros livros didáticos ou literários.

\section{O ENSINO dA CiêNCIA GeOgráficA}

A G eografia como ciência social está diretamente implicada nessas transformações. J á no início dos anos 90, o discurso que ficou conhecido com o rótulo de G eografia C rítica, que postulava uma ciência geográfica de cunho marxista, começou a ser abalado. Surgiram outros enfoques de explicação e interpretação da realidade. Na G eografia, a análise marxista não desapareceu, assim como não desapareceram as chamadas Geografias Tradicionais e Quantitativa, mas como a epistemologia da Geografia está em constante construção, tem-se a linha da G eografia C ultural, com tendências aos métodos fenomenológicos. A tendência, recente em $\mathrm{G}$ eografia, dos estudos fenomenológicos procura apreender o significado do lugar, por exemplo, para os seres humanos. Isto é, o lugar não é apenas algo que objetivamente se dá, mas algo que é construído pelo sujeito no decorrer de 
sua experiência. Por isso, a realidade não é apenas dado objetivo, mas inclui a percepção do meio ambiente enquanto experiência vivida e sentida.

Este enriquecimento das diferentes interpretações na G eografia conduz à necessidade de reformular categorias e conceitos para compreender melhor o movimento da sociedade e para refletir sobre a problemática espacial à luz das contribuições de uma teoria social crítica. C onceitos como os de Estado, Nação, cultura, imperialismo, dependência, centro, periferia e marginalidade - muito importantes no pensamento geográfico - estão sendo questionados, sobretudo com a globalização da sociedade, seja por ganharem conotações substancialmente novas, seja por terem perdido seu poder explicativo. $\mathrm{O}$ mapeamento da narrativa geográfica também não se dá em um único local, mas perpassa as fronteiras linguísticas e geográficas.

\section{GEOGRAFIA ESPAÇO-TEMPORAL}

A G eografia defronta-se, assim, com a tarefa de entender o espaço geográfico em um contexto pós- moderno. O avanço das técnicas, a maior e mais acelerada circulação de mercadorias, de pessoas e de idéias distanciam os homens do tempo e da natureza e provocam um certo "encolhimento" do espaço de relação entre estes homens. Na sociedade pós- moderna, baseada em princípios de circulação e de racionalidade, há um domínio do tempo e do espaço, mecanizados e padronizados, que se tornaram fonte de poder material e social em uma sociedade que se constitui com base no Industrialismo e no Capitalismo.

O controle do tempo e do espaço liga-se estreitamente ao processo produtivo e à vida social. O tempo relaciona-se tanto com a disciplina e a regularidade exigidas no mundo do trabalho quanto com o giro de capital na produção. $\mathrm{O}$ espaço 
está vinculado à criação de um mercado mundial e à redução de barreiras para a expansão do sistema produtivo. Perde, assim, sua significação absoluta no lugar para ganhá-la na lógica do poder da expansão capitalista. Da mesma forma, o tempo concebido progressiva e linearmente foi sendo substituído por um tempo cíclico e instável, em função de que seu sentido passou a ser ligado ao próprio processo produtivo. Instalou-se, assim, uma compreensão e uma vivência de espaço e de tempo relativos.

O tempo é uma categoria cultural construída historicamente. O lugar e o tempo são realidades construídas individual e grupalmente. Todos os lugares e tempos de nossas vidas como indivíduos ou membros dos grupos são construídos socialmente e neles nos construímos. Alguns são mais evidentes: a escola, por exemplo, é um lugar e um tempo de construção histórica, social e geográfica (construídos na vivência e na representação cultural). Em outros termos, o tempo de escola não é uma mera realidade objetiva, é uma realidade psicológica e cultural construída na vivência e representação coletiva. A escola não é apenas o lugar objetivo onde se aprende, é o tempo- espaço subjetivo, vivido culturalmente onde apreendemos a nós mesmos de forma objetiva e subjetiva, individual e coletiva.

Na prática educativa, não é o tempo em si que se tenta apreender, mas a sua relação com o sujeito na medida em que é capaz de questionar e colocar em debate o próprio conceito de sujeito e de participar de sua formação ou de seu esfacelamento:

O espaço é formado por um conjunto indissociável, solidário e também contraditório, de sistemas de objetos e sistemas de ações, não considerados isoladamente, mas como o quadro único no qual a história se dá (S ANTOS, 1996, p. 51).

Na evolução histórica, a escola, enquanto instituição social, está perpassada por um eixo central à ocupação orga- 
nizada de um tempo vazio: o tempo infanto-juvenil, definindo, desta forma, a história educacional como um dos aspectos centrais das transformações socioculturais das formas e das estruturas mais amplas.

É a partir deste ponto que surge uma nova instituição para os novos tempos: a escola atual. Os estabelecimentos de ensino passam a se configurar como uma etapa de um eixo temporal central da vida moderna.

\section{O LUGAR COMO PONTO DE PARTIDA}

No E nsino F undamental, uma nova fase da vida infantojuvenil se inicia. Tudo o que a criança mais deseja é tomar conhecimento das coisas, e esta ansiedade não se resume à vontade de ler, de escrever e de fazer operações matemáticas, mas também à de descrever suas inúmeras indagações sobre o mundo que a cerca, sobre as coisas naturais e humanas, sobre o mundo da televisão, do rádio e do jornal: um mundo que é distante, mas ao mesmo tempo próximo à criança, enfim, um mundo mais complexo do que o ensino tradicional presume. Infelizmente, a escola subtrai as dúvidas das crianças, estabelecendo limites para a possibilidade de pensar. A hierarquia das diferentes escalas espaciais não pode ser ultrapassada e tampouco relacionada com a realidade.

Santos (1977, p.6), em seus estudos sobre o processo ensino-aprendizagem na área de Geografia, verificou duas abordagens teórico metodológicas. A primeira abordagem é a sintética, que se caracteriza por apresentar o estudo da localidade como ponto de partida para o ensino de Geografia e ampliar, gradualmente, as porções do espaço terrestre a serem estudados. A segunda abordagem é a analítica, na qual se trabalha, nos primeiros anos de escolaridade, a superficie terrestre no seu conjunto (ou seja, o que é desconhecido e distante), para depois se chegar ao lugar de convivência. Dentre essas duas abordagens, tem prevalecido, principalmente no 
final dos anos 80 e anos 90, a abordagem sintética, mesmo porque esta é a que mais se aproxima do $\mathrm{C}$ onstrutivismo, em que a ação do indivíduo sobre o objeto é fundamental para a construção do conhecimento.

Todavia, o que pode ser verificado na prática pedagógica do professor é uma hierarquização linear e mecânica do espaço. Assim, estuda-se primeiramente a família, depois a escola, a rua, o bairro, a cidade, o campo, o município, o estado, a nação, o continente e, por fim, o mundo. Há uma sequência que não pode ser transgredida e, na melhor das hipóteses, a criança conseguirá compreender a dimensão do mundo no final do segundo ciclo do Ensino Fundamental (quarta série). Cada escala espacial é ensinada de forma isolada, sem nenhuma relação entre o espaço imediato, próximo e o longínquo, distante.

A aceleração técnica dos meios de comunicação fez da mídia o maior instrumento de informação da maioria da população. A televisão adentra os lares vorazmente, mas as emissoras pouco estão preocupadas se as crianças constróem o conceito de espaço a partir de suas experiências próximas, e muito menos respeitam essa linearidade escalar apregoada pela escola.

S egundo Almeida e Passini (1991), os avanços tecnológicos dos meios de comunicação e circulação proporcionam a aproximação dos espaços pelas interligações existentes entre as diferentes escalas espaciais. Para Ianni (1999), o avanço dos meios de comunicação está atrelado ao mercado mundial, os meios de comunicação foram tomados pelas empresas como o instrumento para concretizar seus objetivos. Para o autor, essa ansiedade do mercado mundial em criar idéias, padrões, valores socioculturais e imaginários planetários através dos meios de comunicação leva à noção de que se vive numa aldeia global. De acordo com os Parâmetros C urriculares Nacionais, editados pelo Ministério da Educação e Cultura (BRAS IL, 1998, p.116), torna-se cada vez mais claro para os educadores que 
não se deve mais trabalhar do nível local ao mundial hierarquicamente. (...) A compreensão de como a realidade local relaciona-se com o contexto global é um trabalho que deve ser desenvolvido durante toda a escolaridade de modo cada vez mais abrangente, desde os ciclos iniciais.

Neste sentido, as diferentes escalas não podem ser compreendidas como objetos únicos e isolados. Não é possível esconder das crianças o mundo quando a televisão apresenta os acontecimentos mundiais em tempo real diante de seus olhos.

O conceito de espaço do cotidiano, ou o imediato concreto utilizado na escola (o que, na G eografia, chama-se de lugar) não abrange a sua dimensão atual. C om a globalização e os avanços técnicos, científicos e informacionais, o lugar não pode ser entendido como uma categoria ou uma entidade que se encerra em si. S egundo SANTOS (1997, p. 273), ele é cada vez mais "objeto de uma razão global e de uma razão local, convivendo dialeticamente".

Não se espera que uma criança de dez anos possa compreender toda a complexidade das relações do mundo com o seu lugar de convívio e vice- versa, no entanto, privá-la de estabelecer hipóteses, observar, descrever, representar e construir suas explicações é uma prática que já não condiz com o mundo atual e com uma educação voltada para a cidadania.

$\mathrm{Na}$ verdade, a idéia seria de uma adaptação na aprendizagem dos conteúdos curriculares. Nos dois primeiros ciclos do Ensino Fundamental o currículo se baseia na paisagem local e no espaço vivido pelas crianças. Conforme Almeida e Passini (1991, p.13), a realidade continua sendo "o ponto de partida e de chegada”. Todavia, esse ensino só será transformador na medida em que o lugar de convivência possibilite à criança o estabelecimento das primeiras relações desse conhecimento com o mundo e vice-versa. 


\section{CuRRículo oculto}

A organicidade curricular pode provocar mudanças por parte dos professores e nos fundamentos do currículo, mais especificamente no que diz respeito às relações entre conhecimento, cultura e poder na educação. O currículo é entendido por muitos professores como sinônimo de programas de ensino, lista de conteúdos ou matriz curricular. Na realidade, existe uma pluralidade de definições e cada uma dessas definições pressupõe valores e concepções implícitas.

Aqui, é preciso reintroduzir uma rápida reflexão sobre a questão do "currículo oculto". Ao fazê-lo, precisa-se ressignificar este importante conceito, uma vez que sua formulação clássica estava estreitamente relacionada à sociedade industrial, e agora se vive em uma sociedade pós-industrial, em um mundo no qual a atividade econômica dominante são os "serviços", onde o industrial e o rural constituem atividades subsidiárias. A questão do consumo no mundo contemporâneo se tornou bem mais significativa do que a questão da produção. Na sociedade dos serviços, a ideologia consumista (concebida aqui como forma de domínio cultural, de exercício de poder e de direcionamento sobre o inconsciente individual e coletivo) torna-se onipresente, mais hipnótica e mais complexa e multifacetada do que as formas que a precederam.

Isso leva a reconhecer o mérito da teoria do currículo oculto em seu contexto histórico, mas trazendo-a para uma nova amplitude, menos relacionada ao adestramento para o mercado de trabalho e mais direcionada ao condicionamento para o mundo consumidor. Assim supera-se a crítica realizada por Apple:

Pois poderíamos descrever a realidade do que é ensinado aos estudantes com clareza excepcional e ainda assim estarmos errados quanto aos reais efeitos que esse ensino tem, se as normas e os valores que organizam e orientam as vidas subjetivas cotidianas dos trabalhadores não fossem as mesmas encontradas na escola. 
A literatura sobre o currículo oculto por causa de seu modelo claramente determinista de socialização e seu foco exclusivo na reprodução, com exclusão de outras coisas que podem estar ocorrendo, tem uma tendência a retratar os trabalhadores como se fossem autômatos inteiramente controlados pelos modos de produção. (APPLE, 1994, p.171)

Ora, em um mundo cuja produção tende a não mais se basear (sequer no segmento industrial) em princípios tayloristas, em que a "linha de montagem" cega, acrítica e obediente é substituída ou pela mecanização ou pela coordenação-supervisão inteligente, é preciso repensar a teoria do currículo oculto em termos de adequação do estudante aos mais complexos esquemas de manutenção do mundo do consumo, com suas prioridades, seus "valores", seus objetivos e, subsequentemente, suas formas de relações interpessoais desejadas.

Assim, o currículo oculto se mantém mais ativo do que nunca, fundado em um anacronismo taylorista, mas já tingido pelas cores da nova ordem global. S eu impacto se dá em um campo mais sutil, subjetivo e ideológico, a partir das demandas da competitividade, da globalização, do domínio-dominado da cibernética e do mais desenfreado consumo desejado ou realizável. E m outras palavras, são os exemplos que damos, as utopias pelas quais nos movemos (ou a falta destas utopias), o que valoramos, as entrelinhas de nossos discursos, a forma como tratamos os demais, a abordagem que fazemos da ciência, a conduta que temos em relação aos processos de aquisição do conhecimento, os elementos mais importantes de nossa ação na escola (ou na família, no que a tange). Os conteúdos são apenas importantes ferramentas, ainda que pareçam, ingenuamente, o foco de nossas ações como professores.

\section{CONSIDERAÇÕES FINAIS}

A Geografia e a Literatura têm muito em comum: em ambas a comparação e o estudo são de fundamental impor- 
tância. O artista, assim como o professor geógrafo, necessita de imaginação e de intuição. A imaginação e a intuição preenchem os vazios que os elos desconhecidos deixam na corrente dos fatos e permitem ao cientista criar hipóteses e teorias que dirigem, com maior ou menor correção e êxito, a busca da mente em seu estudo das forças e dos fenômenos da natureza, submetendo-os, gradualmente, à vontade humana e criando, dessa forma, cultura - esta "segunda natureza" que nos é própria, forjada por nossa vontade e por nossa inteligência.

No presente artigo, todas as escalas se superpõem e estão intimamente relacionadas. As escalas explicativas não se dão de forma linear. Ou seja, não se estuda primeiro a casa, depois o quarteirão, o bairro e assim sucessivamente, até se chegar ao mundo. Todas as escalas estão relacionadas e fazem parte da explicação de qualquer evento ou situação geográfica.

\section{BiBLIOGRAFIA}

ALME IDA, R.D.; PASS INI, E.Y. E spaço geográfico: ensino e representação. 6. ed. São Paulo: C ontexto, 1998.

APPLE, M.W. Políticas culturais e educação. Porto: Porto E ditora, 1994. ÁRIES, P. (1 981). História social da criança e da família. Rio de J aneiro: Zahar

B AC HE LARD, G. (1 884-1962). A poética do devaneio. São Paulo: Martins Fontes: 1988.

BE NJ AMIN, W. Reflexões: a criança, o brinquedo e a educação. São Paulo: Summus, 1984.

BRAS IL. C onstituição (1 988). 25. ed. São Paulo: S araiva, 2000.

CASTRO, I.E. de. O problema da escala. In: CASTRO, I.E; GOMES, P.C.C.; CORRÊA, R.I. (Orgs.). G eografia: conceitos e temas. Rio de J aneiro, Bertrand Brasil, 1995.

CORREAA, R.L.; ROSE NDHAL, Z. G eografia cultural: um século. Volumes 1 e 2. Rio de J aneiro: EdUERJ, 1999.

CAVALCANTI, L. de S. G eografia, escola e construção de conhecimento. São Paulo: Papirus, 1998. (C oleção Magistério: Formação e Trabalho Pedagógico.) 
CAVALHE IRO, E dgard. Monteiro Lobato: vida e obra. 2.v. São Paulo: Companhia E ditora Nacional, 1956.

FOUC AULT. M. História da S exualidade I: a vontade de saber. Rio de J aneiro: Graal, 1988.

LACOSTE, Y. A geografia. In: CHARLET, F. Filosofia das ciências sociais. Rio de J aneiro: Zahar, 1978.

LOBATO, M. A chave do tamanho. São Paulo: Brasiliense, 1947.

MONTEIRO, C.A. de F. O mapa e a trama: ensaios sobre o conteúdo geográfico em criações romanescas. Florianópolis: EDUFSC, 2002.

MORE TI. F. Atlas do romance europeu 1800-1 900. São Paulo: B oitempo E ditorial, 2003.

NUNES, C. Monteiro Lobato: o editor do B rasil. Rio de J aneiro: E ditora C ontraponto: Petrobrás, 2000.

RACINE, J. B.; RAFFESTIN, C.; RUFFY, V. Escala e ação: contribuições para uma interpretação do mecanismo de escala na prática da G eografia. Revista B rasileira de G eografia. Rio de J aneiro, v. 45, n. 1, p. 123-135, jan./ mar. 1983.

SANTOS, M. A natureza do espaço: técnica e tempo: razão e emoção. São Paulo: Editora Hucitec, 1996.

Sociedade e espaço: a formação social como teoria e como mé todo. B oletim paulista de G eografia. S ão Paulo, n. 54, 1977.

THOMPS ON, E.P. Tiempo, disciplina de trabajo y capitalismo industrial. In: Tradición, revuelta y consciencia de clase. Barcelona: E ditorial C ritica, 1979.

ABSTRACT: This article presents a proposal to assist in the teaching of geography based on an interdisciplinary perspective. $G$ eography and Literature were combined in order to enrich students' curriculum in the last stage of secondary education. The data collected suggest the book A chave do tamanho, by Monteiro Lobato, can be used as a relevant didactic resource for the teaching of geography. In addition to facilitating the understanding of the idea of geographic scale, the proposal also opens new doors for the comprehension of the local and global realities.

Keywords: curriculum; G eography teaching geographic scale; literature 